\title{
On the Extent of Environmental Health*
}

\author{
Gonzalo A. Ordóñez\# \\ Pan American Health Organization/World Health Organization, Washington DC, USA \\ Email: gaurodec@netscape.net
}

How to cite this paper: Ordónez, G.A. (2021) On the Extent of Environmental Health. Open Journal of Preventive Medicine, 11, 169-191.

https://doi.org/10.4236/ojpm.2021.115014

Received: March 10, 2021

Accepted: May 18, 2021

Published: May 21, 2021

Copyright $\odot 2021$ by author(s) and Scientific Research Publishing Inc. This work is licensed under the Creative Commons Attribution International License (CC BY 4.0).

http://creativecommons.org/licenses/by/4.0/

\begin{abstract}
Background: Main purpose of this article is to offer information, criteria and conceptual proposals that could clarify the extent or scope of environmental health, and systematize the approaches for its institutional stewardship by environmental health services. Hopefully, it will be useful to managers, professionals, technicians and academics involved in the management, implementation, teaching or research of this multidisciplinary field. Methods: The notion of "environment" is examined, a definition is proposed, and a look is taken at the "green" and "blue" sides of environmental problems. A number of understandings in various countries for "environmental health" are put forth and lists of basic areas for environmental health are analyzed. Results: One finding is that all lists are, in reality, unsystematic groupings of three different constituents: determinants, processes and functions. Consideration of these groupings leads to a homogeneous list of 18 areas and 77 sub-areas. Sets or series are provided for each type of constituent (64 determinants, 18 processes and 25 functions), and their aggregation forms the enormous universe of environmental health activities. On the other hand, certain rules of operation are proposed which make it possible, through a form of algebra, to construct expressions based on the provided sets of constituents. And it becomes possible to employ a common symbolic language for describing or assigning activities in the environmental health services. Conclusions: The article analyses the contemporaneous extent of environmental health.
\end{abstract}

\section{Keywords}

EH: Environmental Health, EHS: Environmental Health Services, EHDet: Determinants, EHPro: Processes, Fct: Functions, EHSA: EHS’ Activity Matrix

${ }^{\star}$ This article is a translation and revision/updating of the Special Report "Salud ambiental: conceptos y actividades" ("Environmental Health: Concepts and Activities"), which was refereed and appeared in Spanish in the Pan American Journal of Public Health, Vol. 7, No. 3 (March 2000). Translation was performed by the author, with permission, and $\mathrm{PAHO} / \mathrm{WHO}$ is not responsible for the translation accuracy.

${ }^{\#}$ Author is former PAHO/WHO environmental health advisor. 


\section{Terminology and Background}

\subsection{The Environment}

Some definitions of "environment" follow:

"en-vi-ron-ment: $n$. 1: the circumstances, objects, or conditions by which one is surrounded 2 a: the complex of physical, chemical, and biotic factors (as climate, soil, and living things) that act upon an organism or an ecological community and ultimately determine its form and survival b: the aggregate of social and cultural conditions that influence the life of an individual or community" [1].

"Environment: The sum of all external conditions affecting the life, development and survival of an organism" [2].

"In its broadest sense, the environment is a major determinant of human health and well-being [...] and unhealthy environments can create substantial morbidity, mortality, and disability [...]" [3].

The term "environment" has in English many (more or less) equivalent terms, like milieu, ambiance, ambient, setting, surroundings, medium, atmosphere and others. For our objectives, we will not use any of them but exclusively the word "environment".

Thinking of planet Earth, the whole of all existing things and living beings (the aggregate of the planet's ecosystems) could be called "physical environment". When humans and their works are not taken into account, one usually talks on "natural environment". It appears that the environment is generally viewed as an "object-centric", and particularly an anthropocentric, concept or relative to something (live or inanimate). The following could be a general approach:

"Environment, for each human being, human group, living or inanimate entity, at a chosen scale, is the whole of the surrounding physical world with its entities (living and/or inanimate and/or man-made) and their actions, interactions and interrelations."

People are immersed in the environment, and they can, for instance:

to know the environment's generalities and details;

to measure environment's parameters;

to usel control those circumstances of the environment which act on mankind's life;

to conservel sustain environment's desirable, positive and pleasant characteristics.

\subsection{Green and Blue Sides}

Interactions as to know, to measure, to usel control and to conservel sustain, bring about the need to manage and solve a multitude of environmental problems. In the second half of the XX century, it became conspicuous the appearance of two different views (even with colors attached) as to the management of environmental problems, particularly in the national and international public sector. 
The green side is worried about what people's activity can do to the natural environment and includes aspects like sustainable development, biodiversity protection, climate change, ozone layer, poverty, demographic dynamics, land management, deforestation, desertification and drought, mountain areas, seas and coast protection, biotechnology, etc. The blue side (brown for some) is concerned about what the environment can do to the health and welfare of people; it has usually been called environmental health, and the discussion of its scope and structure is one of the main goals of this paper. The two sides or points of view are, of course, closely related, frequently embracing overlapping issues. Sometimes the separation or identification of scopes could be deemed difficult or artificial. However, such identification is important because, presently, there is a sort of institutional work distribution in the countries and at international level.

Nowadays the same "environmental health" designation or its equivalents is applied not only to an analytic set of knowledge and practices but also to a system of resources-human, physical, financial and institutional-dedicated to putting into action such knowledge and practices. Therefore, it is convenient to demarcate both aspects, and it could be as follows: call environmental health, or EH, to the analytic set, and environmental health services, or EHS, to the system of resources.

\subsection{Environmental Health}

A number of $\mathrm{EH}$ equivalent denominations exist, for instance: "environment hygiene", "environmental sanitation", "environment protection and development", "health and environment", "environment and health", and others. In the public health domain, the name "environmental public health" is sometimes used. The term "environmental sanitation", still employed in various countries, is prone to confusion because the current practice frequently reserves the word "sanitation" for wastes or excreta management. The term "environment protection and development" is wide enough to include $\mathrm{EH}$, but by its very breadth, it could also embrace the entire "green" universe. The "health and environment" and "environment and health" names might receive as many meanings as many could be the interrogated persons or institutions. For some, "health and environment" signifies, literally, (human) health on the one side and environment on the other, in each case with whatever could be the arbitrarily designated range. The reverse may occur with "environment and health". According to others, "health and environment" implies the influence of environment on health, but with an emphasis on health, and there is no lack of arguments to claim that "environment and health" points at an emphasis on environment. In summary, just "environmental health" is probably preferable.

\subsection{Environmental Health Services}

Within virtually every public governmental sector some kind of nationwide technical-administrative body exists, or more than one, with name, structure and in- 
stitutional position largely varying from country to country, but anyway in charge to administer actions identifiably belonging to environmental health. Also, there exist, usually, local bodies (in regions or states or provinces or municipalities, etc.) among whose responsibilities are $\mathrm{EH}$ ones. As said above, we will apply to all of these bodies the uniform name of "Environmental Health Services" (EHS). Predictably, the name and affiliation of nationwide EHS throughout the world are diverse and we give some examples (Table 1).

In some cases, the EHS are not given all the political power or means to fully enable them to properly take care of the blue side of the environmental problems, and this is dangerous for public health. One significant aspect which is easily

Table 1. Name/affiliation of some environmental health services (EHS) (alphabetical order by country).

\begin{tabular}{|c|c|c|}
\hline COUNTRY & EHS NAME & PARENT INSTITUTION \\
\hline Argentina (a) & Department of Environmental Health & Ministry of Health and Social Action \\
\hline Botswana (b) & Environmental Health Unit & Ministry of Health \\
\hline Brazil (b) & Department of Policy and Environmental Evaluation & $\begin{array}{l}\text { Ministry of Environment, Water Resources } \\
\text { and Legal Amazonia }\end{array}$ \\
\hline Chile (a) & Environmental Health Division & Ministry of Health \\
\hline Colombia (a) (Atlantic Gov.) & Environment and Health Division & Atlantic Health Administrative Department \\
\hline Costa Rica (a) & Directorate of Human Environment Protection & Ministry of Health \\
\hline Dominican Republic (a) & General Directorate of Environmental Health & $\begin{array}{l}\text { State Secretary for Public Health and Social } \\
\text { Service }\end{array}$ \\
\hline Egypt (b) & Department of Environmental Health & Ministry of Health and Population \\
\hline Indonesia (b) & Directorate of Environmental Health & Ministry of Health \\
\hline Ireland (e) & Department of the Environment and Local Government & $\begin{array}{l}\text { Ministry for the Environment, Heritage and } \\
\text { Local Government }\end{array}$ \\
\hline Mexico (a) & General Directorate of Environmental Health & Secretary's Office of Health and Social Service \\
\hline Morocco (f) & Department of the Environment & $\begin{array}{l}\text { Ministry of Energy, Mines, Water and } \\
\text { Environment }\end{array}$ \\
\hline Panama (a) & Assistant General Directorate of Environmental Health & Ministry of Health \\
\hline Peru (a) & General Directorate of Environmental Health & Ministry of Health \\
\hline Philippines (b) & Environmental Health Service & Department of Health \\
\hline Portugal (d) & Portugal Environmental Agency & $\begin{array}{l}\text { Ministry of Environment and Territorial } \\
\text { Arranging }\end{array}$ \\
\hline Puerto Rico (a) & Auxiliary Secretary's Office for Environmental Health & Department of Health \\
\hline United States $(c)$ & Environmental Protection Agency & Federal Government \\
\hline
\end{tabular}

(a) After documents of the Regional Meeting on Institutional Development of the Ministries of Health's environmental health units. PAHO/WHO. San Juan, Puerto Rico, August 1998. (b) After documents of the WHO Interregional Meeting on the guidelines for the strengthening of environmental health services towards improved governmental action on environmental determinants of health. Geneva, Switzerland, May 1998.

(c) https://www.epa.gov/aboutepa (retrieved August 2010). (d) https://apambiente.pt/index.php?ref=16 (retrieved August 2010).

(e) https://www.gov.ie/en/help/departments/ (retrieved August 2010). (f) https://www.environnement.gov.ma/fr/\# (retrieved August 2010). 
neglected by local or national governments is the maintenance and conservation of physical installations or qualified human resources.

\section{Environmental Health Definitions}

A paper published by the National Institute of Environmental Health Sciences, NIEHS [4] advances that "A broad definition of environmental health encompasses not only the adverse effects associated with exposure to chemicals in air, food, and water but also the interaction of these exposures with genetic sensitivities and nutrition."

The following was found in an overview of practice [5]: "Environmental health is a relatively new term, which has been used to define both a condition affecting human health and a professional discipline. Inevitably, it has come to mean different things for different people and different countries". According to this same reference, the following definition was proposed at a World Health Organization, WHO, Consultative Meeting in Sofia, Bulgaria, 1993:

"Environmental health comprises those aspects of human health, including quality of life, that are determined by physical, chemical, biological, social and psychosocial factors in the environment. It also refers to the theory and practice of assessing, correcting, controlling and preventing those factors in the environment that can potentially affect adversely the health of present and future generations." See also reference Yassi, A. et al. [6].

\section{The Multidisciplinary Field of Environmental Health}

The EH field is so wide and complex that its research, theory and application need the involvement of many sciences, professions and technologies, for instance: sanitary engineering, medicine, public health, civil engineering, hydraulics, chemistry, physics, computing, microbiology, biology, epidemiology, toxicology, ergonomics, statistics, nutrition, genetics, toxico-genomics, molecular biology, proteomics, nanotechnology, economics, law, education, sociology, psychology, urban planning, business management, etc. In many cases, these professions evolve to new specializations, as environmental engineering, environmental medicine, environmental toxicology, environmental oncology, environmental education, environmental management, environmental health nursing, and even to new concepts, as environmental justice and environmental policy.

\section{Recent History of the Scope of Environmental Health Problems}

Below are given a few examples of the approach of international organizations and some countries on the subject of the EH extent.

\subsection{Pan American Health Organization (PAHO/WHO)}

The following broad categorization in areas was applied to $\mathrm{EH}$ towards the end of the 80's: 
Water supply and sanitation;

Solid wastes;

Environmental risks for health;

Workers health.

A document of 1994 [7] contains the following list of 22 program areas, which are said to "summarize all of the Sanitation Technicians activities, according to information gathered in the [American] Region's countries":

Drinking water;

Excreta, wastewater and storm water;

Solid wastes;

Food hygiene;

Improvement of housing and human settlements;

Vector control;

Zoonosis control;

Public buildings sanitation;

Sanitation of tourism and recreation places;

Sanitation applied to sea, air and land transportation;

Sanitation planning for urban and rural development;

Workers health, hygiene and safety;

Toxic materials control;

Ionizing radiation;

Accidents prevention;

Environmental impact and health;

Sanitary steps in special cases (natural and technological disasters, migra-

tions, epidemics, etc.);

Environmental pollution prevention and control;

Prevention of water resources pollution;

Prevention of flora, fauna and landscape pollution;

General and management activities;

Promotion of community involvement and sanitary and environmental education.

PAHO/WHO [8] used for EH in 1998 the designation "Environmental Protection and Development". About technical cooperation, it listed the following items (as condensed by the author):

Community mobilization and inter-sectoral coordination;

Education in environmental epidemiology and toxicology;

Leadership and advisory role of ministries of health for environmental health planning and programming, and in developing local capabilities for the operation and maintenance of systems and services;

Projects on the effects of environment on children's health;

Primary environmental care activities;

Updating of standards and regulations governing the quality of environmen- 
tal services and products;

Mechanisms to gather, analyze and utilize data and indicators on the quality of the environment;

Taking action in the countries on factors that adversely affect workers' health; Water supply and sanitation to expand service coverage, improve the bacteriological quality of drinking water and intensify activities in rural areas and for indigenous populations;

Improving municipal solid waste management.

\subsection{World Health Organization (WHO)}

When the United Nations Conference on Environment and Development (UNCED) convened in Rio de Janeiro, 1992, WHO presented the book Our Planet, Our Health [9] containing the main following chapters with a very thorough treatment of green and blue issues:

1) Health, environment, and development;

2) Global challenges to health and the environment;

3) Food and agriculture;

4) Water;

5) Energy;

6) Industry;

7) Human settlements and urbanization;

8) Transboundary and international problems.

\subsection{WHO/Europe Regional Office}

Euro/WHO has the conceptual model DPSEEA (Driving Forces-PressuresState-Exposure-Effects-Actions) [10] of health-environment interlinks to help design a system of $\mathrm{EH}$ indicators within the decision-making context. The driving forces component refers to the factors that motivate and push the environmental processes involved, and they generate pressures that often modify the state of the environment. This state creates an exposure that poses risks to human well-being only when people are present both at the place and at the time that the hazard occurs. Such exposure leads to a wide spectrum of health effects, acute or chronic. In face of the environmental problems and its health effects society attempts to adopt and implement a range of actions, for example, to reduce or control the hazards concerned, or preventive ones to eliminate or reduce the forces that drive the system.

\subsection{The Agenda 21}

This document [11], also presented at the UNCED, devoted to the environmental health area (although not with this explicit name) seven out of 14 chapters of Section II, "Conservation and Management of Resources for Development":

Protection of the atmosphere (Chapter 9);

Integrated approach to the planning and management of land resources 
(Ch. 10);

Protection of the quality and supply of freshwater resources: application of integrated approaches to the development, management and use of water resources (Ch. 18);

Environmentally sound management of toxic chemicals, including prevention of illegal international traffic in toxic and dangerous products (Ch. 19); Environmentally sound management of hazardous wastes, including prevention of illegal international traffic in hazardous wastes (Ch. 20);

Environmentally sound management of solid wastes and sewage-related issues (Ch. 21);

Safe and environmentally sound management of radioactive wastes (Ch. 22).

\subsection{Three International Organizations}

Information was collected by the author (Table 2) in order to summarize what three organizations reported (c. 1993) as the scope of environmental health.

Table 2. The scope of environmental health, according to some international organizations (c. 1993).

\begin{tabular}{|c|c|c|}
\hline PAHO/WHO & EURO/WHO & USAID/WASH \\
\hline Water and sanitation & Water and sanitation & Water and sanitation \\
\hline Solid wastes & & Solid wastes \\
\hline $\begin{array}{l}\text { Control of environmental } \\
\text { risks for health }\end{array}$ & World environment's troubles & \\
\hline Workers health & & Workers health \\
\hline Housing hygiene & Urban environment's development & \\
\hline \multirow[t]{2}{*}{ Water quality } & Water quality & \\
\hline & Food innocuousness & Food hygiene \\
\hline \multirow[t]{4}{*}{ Environmental impact } & Environmental impact & \\
\hline & Outside air quality & Air pollution \\
\hline & Inside air quality & \\
\hline & Hazardous chemical materials & Hazardous materials \\
\hline \multirow[t]{6}{*}{ Hospital wastes } & Hazardous wastes & \\
\hline & Biotechnology & \\
\hline & Urgent help & Wounds \\
\hline & Less contaminant technologies & \\
\hline & & Wastewater \\
\hline & & Tropical diseases \\
\hline
\end{tabular}

$\mathrm{PAHO} / \mathrm{WHO}=$ Pan American Health Organization/World Health Organization; EURO/WHO $=$ WHO Regional Office for Europe; USAID/WASH = Water and Sanitation Program of the US Agency for International Development. 


\subsection{Ireland}

The Department of the Environment and Local Government [12] works mainly on $\mathrm{EH}$ issues as these:

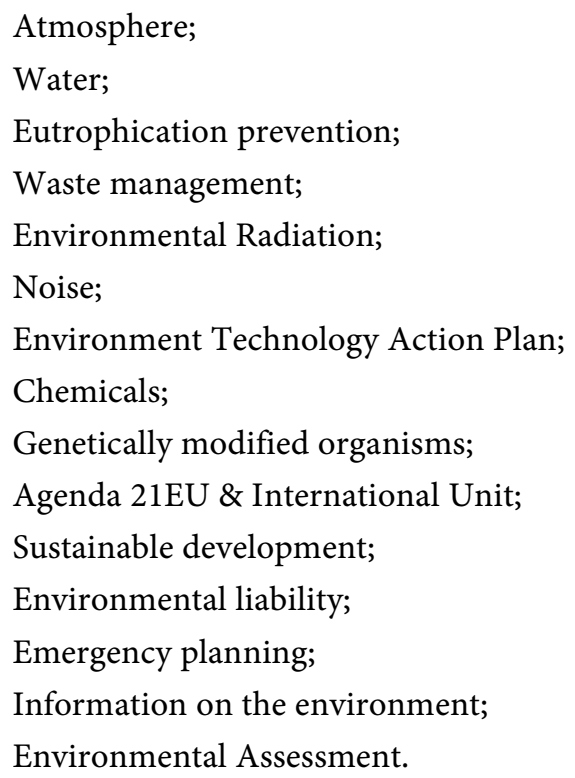

\subsection{Morocco}

The Department of the Environment [13] is advancing a number of law projects in order to get a legal basis for the management of green and blue issues like these (condensed by the author):

Atmospheric pollution;

Accidental sea pollution;

Wastes management and disposal;

Environmental impact;

Production/use of plastic bags;

Coast protection;

Surface water quality (incl. water for human consumption, irrigation and fish farming);

Quality parameters for domestic and some industrial wastewaters.

\subsection{Portugal}

The Portugal Environmental Agency [14] manages green and blue issues. It proposes, develops and monitors the implementation of environmental policies, particularly in (condensed by the author):

Health and transportation sectors;

Climatic change;

Ozone layer;

Air quality;

Noise prevention and control; 
Wastes management;

Contaminated soil reclamation;

Integrated pollution prevention and control;

Serious industrial risks prevention;

Environmental and population safety;

Ecological labeling, ecological purchasing, voluntary systems for environmental management;

Environmental impact assessment;

Environmental liability;

Risk management (technological, chemical, genetically modified organisms' risks);

Alert network for radiological and nuclear risks;

Environmental education;

Protection of sea areas;

Environmental regulations and permits.

\subsection{The United States}

The United States Environmental Protection Agency (EPA) [15] indicates that its mission is "to protect human health and the environment". Also, it gives [16] the following alphabetical list of topics (which contains about 219 subtopics and a very large number of detail issues):
Air;
Cleanup;
Compliance \& Enforcement;
Economics;
Ecosystems;
Emergencies;
Environmental Management;
Environmental Protection Agency;
Environmental Technology;
Government;
Human Health;
Industry;
International Cooperation;
Pesticides;
Pollutants;
Toxics;
Pollution Prevention;
Radiation and Radioactivity;
Research;
Treatment \& Control;
Wastes;
Water. 
It is interesting to note that certain environmental concerns of the United States (see, below, examples of "green" and "blue" topics) go to federal administrations other than EPA, and also to tribal, state or local agencies [17]. EPA works cooperatively with many of these instances.

Some "green" issues.

Endangered Species Act is primarily managed by the U.S. Fish and Wildlife Service;

Wildlife and destruction of wetlands has much to do with the U.S. Army Corps of Engineers;

Situations of human development and wildlife such as foxes, birds, etc. are managed by state or local wildlife offices;

Information on gardening or farming is offered by the local Agricultural Extension office.

Some" blue" $(E H)$ issues:

Environment inside the workplace is under the Occupational Safety and Health Administration (OSHA);

Safety of products used in daily life is the concern of the Consumer Product Safety;

Commission;

The Federal Insecticide, Fungicide and Rodenticide Act is managed cooperatively by EPA;

and the Food and Drug Administration(FDA);

Safety of food and any substance applied to human body is a concern of FDA;

Noise complaints are mainly regulated by local governments (e.g., cities' and counties');

Dust in roads is a local issue;

Issues about local landfill are for the county environmental agency.

\section{Lists of Environmental Health Problems}

Whenever EHS's officials are organizing or modifying activities at institutional level, they will need to deal inter alia with the following fundamental aspect: What is the list of areas or issues (environmental health problems) to be managed? For some countries the list will be rather short in order to prioritize resources. Others would like to concentrate on the existing problems and postpone for later action what could arise from upcoming stages of development. Others may want to manage a very wide list with the aim of not leaving out any $\mathrm{EH}$ issue. It could happen that the national level EHS is concerned mainly with policies and regulations, while the local level EHSs perform the implementation, maintenance, etc. The author will now intend to offer assistance for the preparation of the list, and to that end a compilation and systematization of EH components will be proposed. 
Through the examination of a number of documents as those mentioned above and others (e.g., Schaefer, M. [18]), a list can be built (18 areas and 77 sub-areas (Table 3). Probably this list encompasses the vast majority of items one would need to include in the "environmental health" concept.

Table 3. Inhomogeneous list of areas and sub-areas for environmental health problems.

1) Production and protection of safe drinking water

- Surface water sources

- Transportation and storage

- Ground water

- Water treatment

- Disinfection (including in situ electrolytic methods)

- Water distribution

- Water quality (standards, control and surveillance)

- Industrial water

- Management and technology

- Rate policies

2) Sewerage and excreta disposal

- Wastewater collection and transportation

- On-site excreta disposal

- Storm water collection and management

3) Water resources and pollution

- Management of basins and collection areas

- Hydrogeology

- Water bodies pollution (standards for discharge, control and surveillance)

- Wastewater treatment

- Wastewater disposal

- Industrial effluents

- Water conservation, recycling and reuse

- Management and rates

4) Solid wastes and soil protection

- Standards

- Household solid wastes collection and transportation

- Household solid wastes treatment and disposal

- Management of industrial solid wastes

- Recycling, reduction, reuse and rejection

- Soil pollution

5) Air pollution

- Standards

- Monitoring

- Emission controls

- Transportation emissions management

- Inside air pollution 


\section{Continued}

6) Food innocuousness

- Food hygiene (standards for production, distribution, preparation, retailing, education)

- Food-induced illnesses (absence of hygiene)

- Pesticide use

- Slaughterhouses control

7) Workers health and safety

- Occupational hazards and risks

- Work place contaminants

- Ergonomics

- Industrial and agro-industrial safety

- Standards and remedial measures

8) Chemical safety and hazardous wastes

- Management of hazardous chemical materials

- Pesticides management

- Hazardous wastes management

- Hospital wastes management

- Standards

9) Human settlements and housing

- Standards

- Housing hygiene

- Hygiene of public buildings and recreational areas

- Repairing

- Development

10) Vector control and veterinary public health

- Vector management in public health

- Arthropods and rodents

- Zoonosis control

11) Ionizing and non-ionizing radiation

- Standards

- Management of radioactive wastes

- Radioactive sources in health services

- Industrial radioactive sources

- Electromagnetic fields and health

12) Noise pollution

- Standards

- Industrial noise

- Transportation noise

- Noise by other sources

13) Tourism and environmental health

- Beaches

- Tourists lodging 


\section{Continued}

- Swimming pools

- Health control in ports

14) Urban planning and land use

- Policies for urban and rural development

- Environmental impact assessment

15) Transportation safety

- Accident prevention

16) Drugs quality

- Laboratories' bio-safety

17) Global environmental aspects

- Ozone layer depletion

- Greenhouse effect

- Energy and environment

- Transboundary pollution

- Environmental management

18) Disasters

- Prevention and mitigation of technologic and natural disasters

\section{Determinants, Processes and Functions}

However, upon analysis of Table 3 and of virtually any other list similar to the above-mentioned ones, the fact appear that they are all "inhomogeneous" because those environmental health problems contain an unsystematic assemblage of three conceptual categories or types the author calls constituents. Environmental Health determinants, for instance "water quality", "household solid wastes" or "Vibrations"; Environmental Health processes, as "treatment", control" or "education"; and functions, like "feasibility studies" or "promotion". Suggested lists of constituents are mentioned further down.

Determinants (EHDet) are the physical environmental factors or facts to be acted upon in order to satisfy EH-related human beings' needs. See in Table 4 a list or series of 64 determinants, arbitrarily ordered and arranged in 20 groups. Criteria to identify a determinant: (a) It has to be described by a noun or by a nominal sentence, without adjectives; (b) It has to be of a reasonably detailed level. e.g.: Instead of "wastes", put "solid wastes", "wastewater", etc.; (c) It will not mention processes or functions such as facilities, plants, etc. (e.g., "landfill", "waste treatment", "final design").

Processes (EHPro) are sets of interventions, in the frame of functions, applied to EHDet in order to define/solve an environmental health problem and an EHS activity. See in Table 5 a series of 18 processes, operatively ordered.

Functions $(F c t)$ are sets of management actions applied to processes in order to have a full tool to be applied on determinants and so define an EHS activity. See in Table 6 a series of 25 functions, according to an assumed operational order. Functions are not specific to environmental health because they enumerate 
Table 4. The series of environmental health determinants (EHDet). This set comprises the first of the three constituents found to define an EHS activity. By taking action on determinants, which are real world factors, one or more problems related to environmental health get satisfied.

\section{DETERMINANT AND SYMBOL}

DD01: Water for human consumption
D01 Surface water
a) Rain water
b) Mist water

D02 Ground water

D03 Water quality

DD02: Liquid wastes
D04 Wastewater

D05 Excreta

D06 Storm water

D07 Industrial effluents

DD03: Water resources

D08 Basins and collection areas

D09 Pollution of aquatic bodies
a) Eutrophication
b) Invasive species

DD04: Solid wastes and soil

D10 Household solid wastes

D11 Industrial solid wastes

D12 Agro-industrial solid wastes
D13 Soil pollution
a) Roads
b) Soil degradation

DD05: Food products, water excepted
D14 Foods
a) Producers

b) Manipulators

e) Restaurants

c) Factories

d) Markets

f) Popular fairs

D15 Food induced diseases

D16 Food's harmful biological agents

D17 Other food's toxic agents

DD06: Work environment

D18 Workers environment a) Informal sector

D19 Workplace contamination

DD07: Atmosphere

D20 Vehicle emissions and immisions

D21 Industrial emissions and immisions

D22 Other contaminant emissions

a) Forest fires

D23 Outside air contamination

a) Dust on roads

D24 Inside air contamination

a) Smoking

a) Green buildings

a) Mold
DD08: Human settlements and housing

$$
\text { D25 Housing }
$$

D26 Public buildings and recreational areas 


\section{Continued}

D27 Other buildings and special establishments

a) Industry b) Commerce

c) Education

d) Research

e) Cemeteries

DD09: Chemical products and hazardous wastes
D28 Toxic and dangerous products
a) Endocrine disruptors

D29 Pesticides

D30 Hazardous waste

a) Batteries b) Fluorescent bulbs

D31 Medical wastes

DD10: Vectors

D32 Insects and other disease transmitters
D33 Zoonosis
a) Urban rodents
b) Bed bugs
c) Diptera

DD11: Ionizing and non-ionizing radiations

D34 Radioactive wastes

D35 Health services' radioactive sources

D36 Industrial radioactive sources

D37 Low frequency electromagnetic fields

D38 Other electromagnetic fields

a) Cell phones

DD12: Noise and vibrations

D39 Noise pollution of industrial origin

D40 Noise pollution of transportation origin

D41 Noise pollution from other sources

D42 Vibrations

DD13: Tourists and travelers

D43 Beaches and other recreation sites

D44 Hotels

D45 Swimming pools

D46 Ports

DD14: Cities, territories and human groups

D47 Urban milieu

a) Suburban sprawl

b) Events

D48 Territory arrangement and natural world

D49 Settings and their physical, psycho-social and ethical aspects
a) Municipalities
b) Schools c) Institutions
d) Corporations
e) Scenery f) Environmental related stress

D50 Political, economic, financial and legal milieu

a) International agreements and guidelines $\quad$ b) ISO standards

DD15: Vehicles

D51 Traffic accidents
D52 Transporters
a) Tourism boats

DD16: Medical and household products

D53 Drugs, cosmetics and other

a) Tobacco b) Toys safety

DD17: The planet 
D54 Ozone layer

a) Ultraviolet radiation

D55 Greenhouse effect/climate change

D56 Energy use

D57 Transboundary contamination (particularly by sea or air)

D58 Transboundary movement of hazardous materials or wastes

D59 Deforestation

DD18: Disasters

D60 Anthropic disasters and emergencies

a) Terrorism

D61 Natural disasters and emergencies

DD19: Other

D62 Other determinants

a) Globalization

DD20: Environmental Health Services

D63 Environmental health entities, in general

D64 Water and sanitation entities

DD99: DD01 to DD19

Note: In addition to the general and specific range of each determinant, a few particular instances of interest are annotated with small letter. These do not necessarily form new detail levels but rather constitute random items emerging from practice.

the steps for any projects' three typical phases (i.e., foresight, materialization, use, all of that under a direction-function).

Please notice that each item in Tables 4-6 has a code name (symbol) formed by the letters D, P or F (from Det, Pro and Fct) and a sequential number. Evidently, an adequate list of elemental activities could be generated, for instance, taking one determinant at a time and applying on it one or more adequate processes and functions, systematically. The lists' items could be endowed with additional levels of detail, assigning to them suitable sub-codes.

From the above it can be seen that the DPSEEA model (paragraph 4.3), when looked from the point of view of the three constituents, is also inhomogeneous. The "driving forces" are what we call determinants, along with the pressures, state, exposure and effects-all of them part of EH problems. And the "actions" are the processes and functions of the EHS.

\section{The EHSA Matrix}

Theoretically, the three constituent types could be viewed as the three dimensional arrangement $\{\mathrm{fct}, \mathrm{pro}$, det\}, subject to special operational rules and such that each triple coordinate defines an activity of the environmental health services. For the sake of simplicity, a graph is given of just a two-dimensional arrangement, the "Environmental Health Services' Activity Matrix", or EHSA Matrix (Figure 1). Each cell would contain an activity to be undertaken by the services, originated by the intersection of rows (determinants) and columns (functions and processes). This way, EHS Activities are each elemental combination 
Table 5. The series of environmental health processes (EHPro). This set comprises the second of the three constituents found to define an activity of environmental health services. Processes are interventions (guided by functions) on determinants.

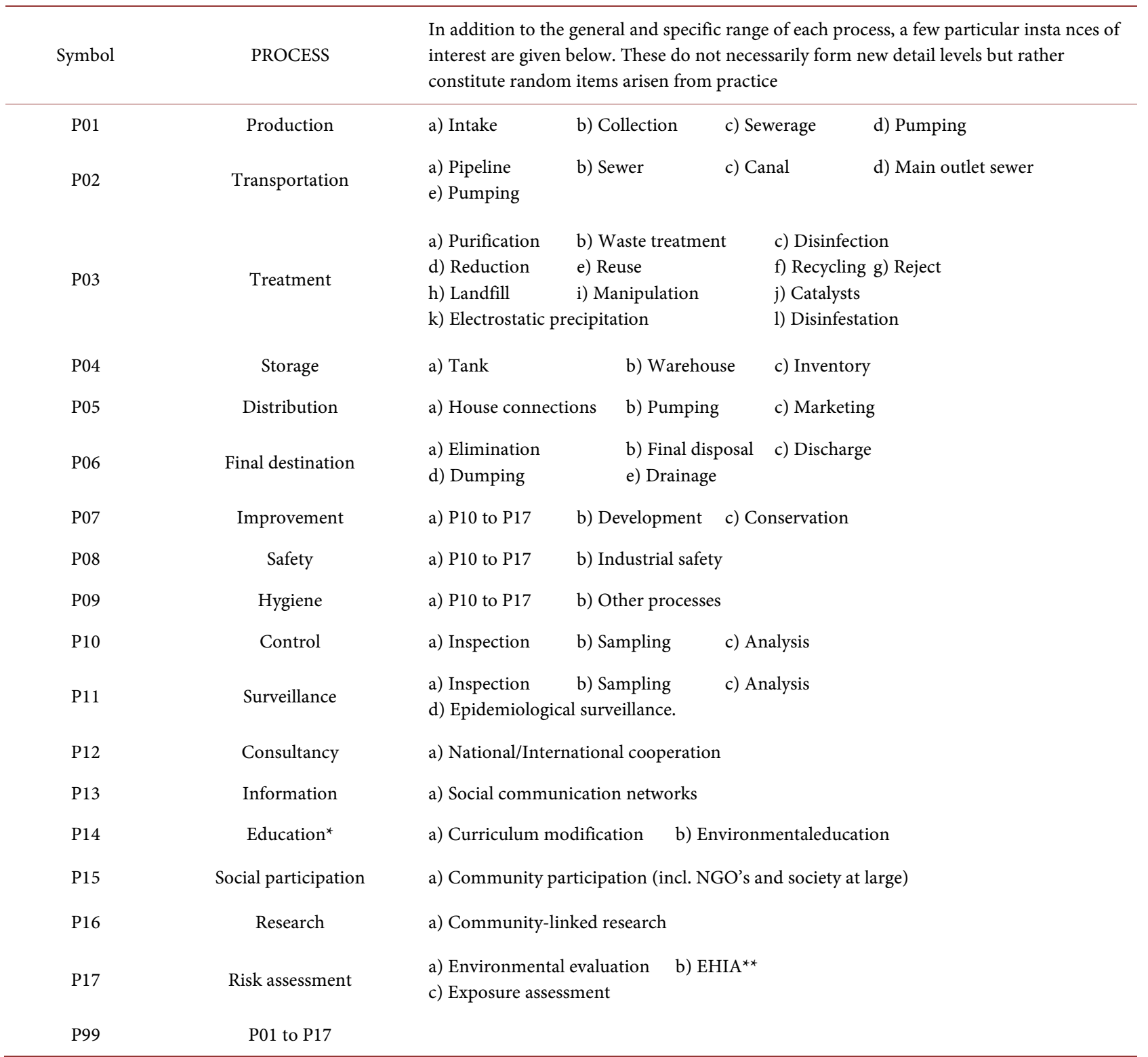

P01 to P09: "hardware"; relatively high investment. P10 to P17: "software"; relatively low investment. *Formal, no formal, informal. ${ }^{* *}$ Environmental health impact assessment. Apply (e.g.): EHProof EHProEHPro (of)(for)(on) EHDet.

stemming from a function acting on a process and on a determinant. Such activities have the ability to handle a specific environmental health problem and, therefore, are the EHS's raison d' être. Of course, each one of them must have a person in charge, an objective, a timeframe, resources and tasks. In practice, EHS will usually work with activity aggregates to be entrusted to persons or units.

\section{The EHSA Algebra}

Operational rules for EHSA's. This is a proposal intended to build a formalization mechanism leading to something like an algebra, which could allow the 
Table 6. Function series (Fct). This set comprises the third of the three constituents found to define an activity of environmental health services. Functions are management actions on processes, thus on determinants.

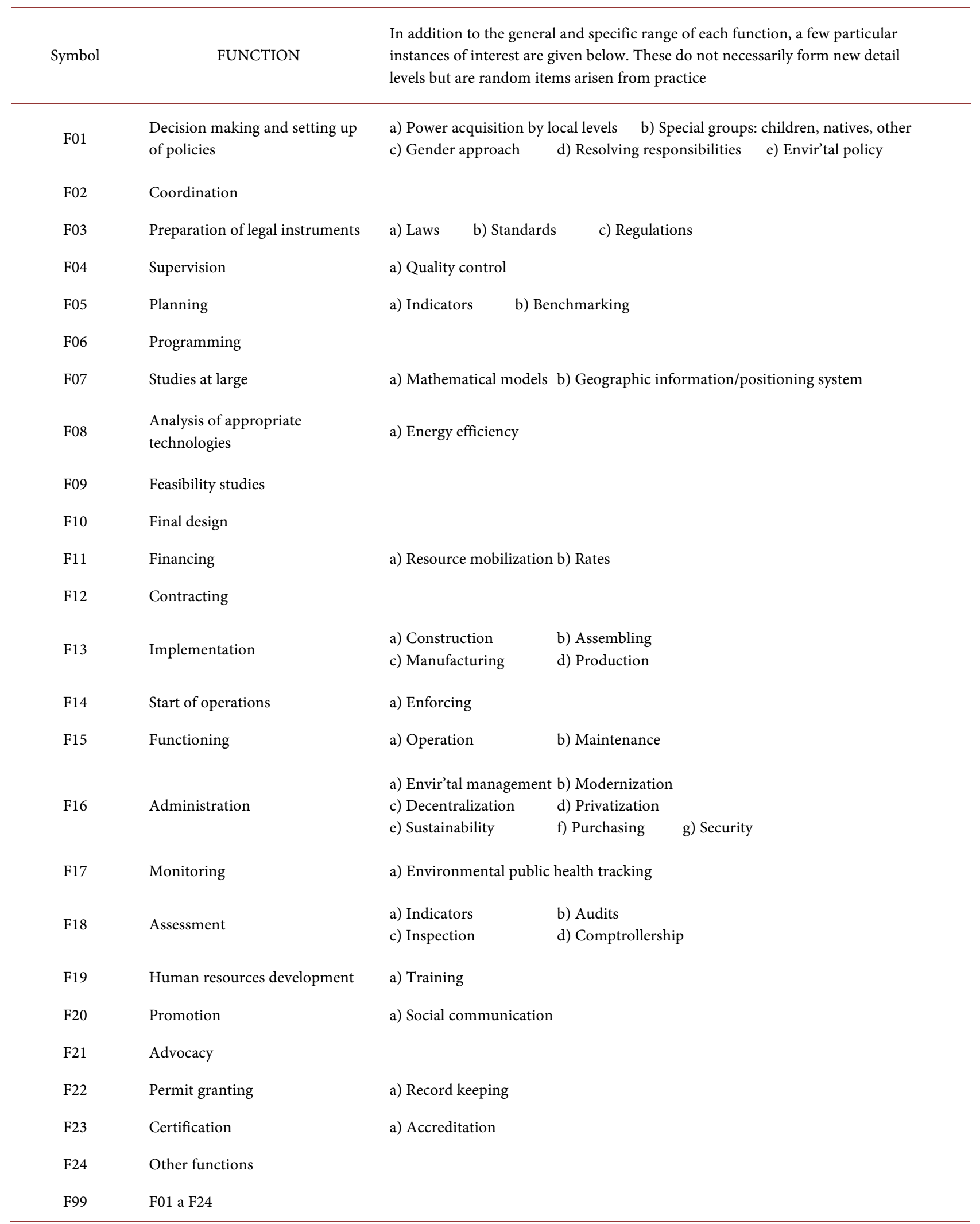

F01 to F04: Direction; F05 to F10: Foresight; F11 to F14: Materialization; F15 to F23: Use. Apply (e.g.): Fct for Fct; Fct for EHPro. 


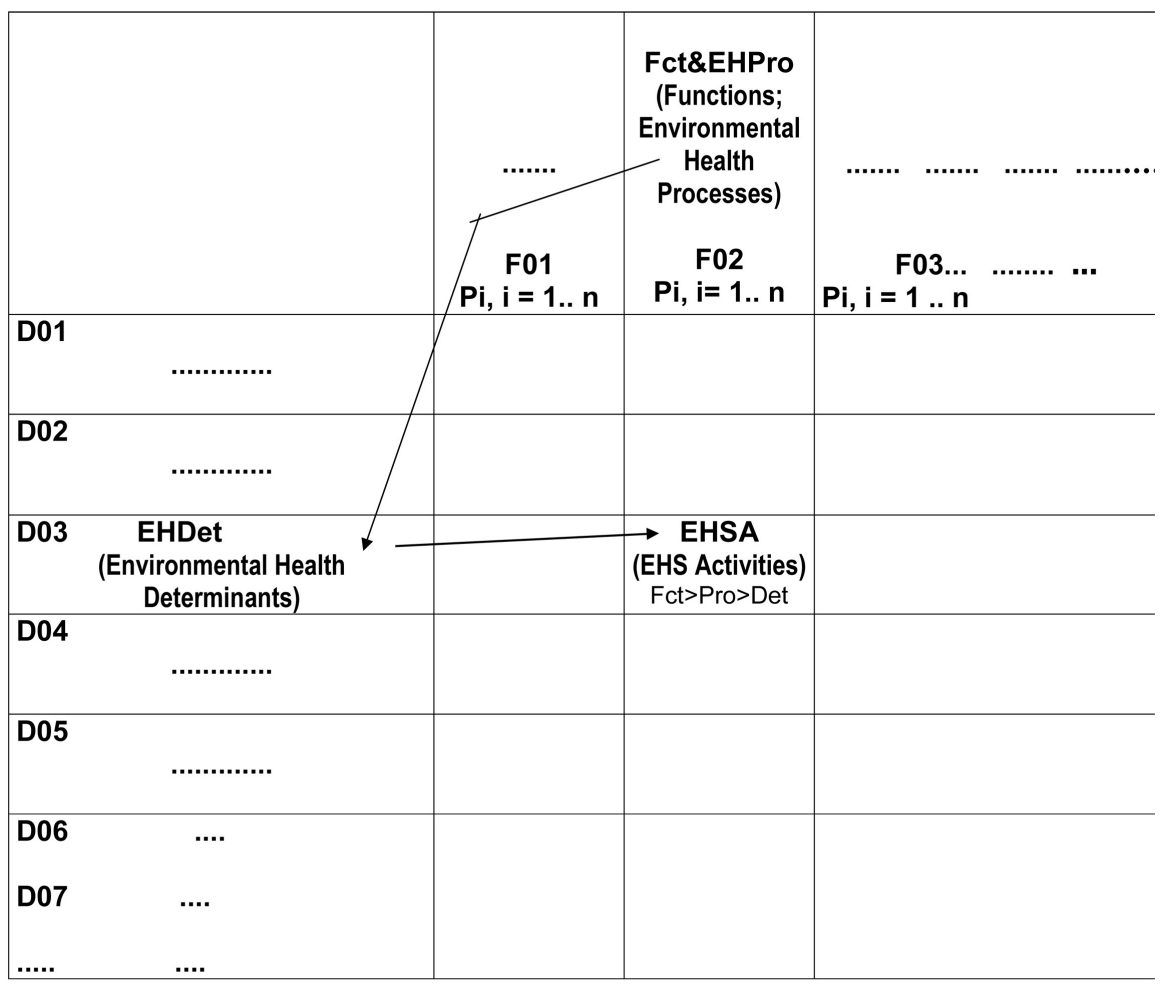

Figure 1. EHSA matrix (Environmental health services' activities matrix). This matrix shows how an activity (each of the cells) is generated by the intersection of a column (functions and processes) and a row (determinants). As an example (not shown in the figure), the function "Feasibility studies" (F09) applied on the process "Treatment" (P03) give a column, and this column, intersected with the determinant "Wastewater" (D04), a row, originates an activity which could be phrased as "Feasibility studies for a wastewater treatment facility".

usage of a mathematical system of symbols to denote constituent's combinations. Rules are:

- The name of each EHSA results from the intersection of a row and column in the matrix. The conventional order in writing will be, from left to right: Fct, EHPro and EHDet.

- Symbol "greater than" ( $>$ ) will denote the application of a constituent to another. This could, for instance, be interpreted as "for", "of", "on" or "about".

- Constituent's grouping will be denoted by the summation symbol (+). A large, same type constituents' set can be simply indicated with "to" between the set's ends. However, if more than one EHDet, they will be enumerated one by one, separated by commas.

- For the sake of brevity, the full Fct list will be denoted by F99 and the full Pro list will be denoted by P99. As to determinants, each area has a name (e.g., "Water resources" or "Tourists"). The full Det list (excluding DD20) will be denoted as DD99.

- The various constituents' grouping levels will be indicated by parentheses ( ), square brackets [ ] and brackets \{\}, from inside to outside. 
- It is permissible to apply one or more Fct over one or more Fct (e.g., F05 > F19) and also to apply one or more Pro over one or more Pro (e.g., P07 > P13).

- In the EH context virtually no combination without Det at the right hand side of the expression will make sense. However, it is possible to have combinations without Fct or Pro.

- Of course, not all possible combinations with Det make sense-for instance, $\mathrm{P} 02>\mathrm{D} 08$ or $(\mathrm{F} 12>\mathrm{P} 06)>\mathrm{D} 32$. (It can be estimated, in principle, the existence of some 14,000 possible [elemental] activities, which would form the EH universe).

Table 7. Some aggregates found in existent latin-american environmental health service units, and its equivalent in terms of determinants, processes and functions. (Descriptions given by the respective EHS were used to build the symbolic expressions, and the aggregate is the name of a unit; not all of the aggregates are necessarily examples to follow as good models. Notice that sometimes a clear relationship does not exist between the unit name and its de facto activity field).

\begin{tabular}{|c|c|}
\hline$A G G R E G A T E$ & SYMBOLIC EXPRESSION FOR THEDE FACTO ACTIVITY FIELD \\
\hline Program for Drinking Water Quality Control & $=\mathrm{P} 07>\mathrm{D} 03$ \\
\hline $\begin{array}{l}\text { Program for Environmental Health and } \\
\text { Sanitary Control and Surveillance }\end{array}$ & $=\{[\mathrm{F} 22>(\mathrm{P} 01$ to $\mathrm{P} 06)]+[\mathrm{P} 10$ to $\mathrm{P} 17]\}>(\mathrm{D} 28, \mathrm{D} 29, \mathrm{D} 35)$ \\
\hline Unit for Risk's Control in Food and Beverages & $=\{[[\mathrm{F} 22>(\mathrm{F} 13+\mathrm{F} 15)]>(\mathrm{P} 01$ to $\mathrm{P} 06)]\}>\mathrm{D} 14\}+[(\mathrm{P} 10$ to $\mathrm{P} 17)>(\mathrm{DD} 05, \mathrm{DD} 13)]$ \\
\hline Program for Basic Sanitation & $=\mathrm{F} 20>[(\mathrm{P} 11>\mathrm{D} 03)+(\mathrm{P} 03+\mathrm{P} 06)>\mathrm{D} 05]$ \\
\hline $\begin{array}{l}\text { Program for the Environment's Effects on } \\
\text { Health }\end{array}$ & $=\{[(\mathrm{F} 06+\mathrm{F} 13)>\mathrm{P} 16]+\mathrm{F} 03+\mathrm{F} 07\}>\mathrm{DD} 99$ \\
\hline Unit for Environmental Sanitation & $=(\mathrm{F} 99>\mathrm{P} 99)>(\mathrm{D} 01, \mathrm{D} 02, \mathrm{D} 04, \mathrm{D} 05, \mathrm{D} 10, \mathrm{D} 23, \mathrm{DD} 10, \mathrm{D} 37)$ \\
\hline Unit for Worker's Hygiene and Safety & $\begin{array}{l}=\mathrm{F} 99>\{[(\mathrm{P} 08+\mathrm{P} 09)>\mathrm{D} 18]+[(\mathrm{P} 03+\mathrm{P} 07)>\mathrm{D} 19]+[(\mathrm{P} 07+\mathrm{P} 08+\mathrm{P} 09)>\mathrm{DD} 08]+ \\
[\mathrm{P} 99>(\mathrm{DD} 11, \mathrm{DD} 12)]+[(\mathrm{P} 08+\mathrm{P} 09)>\mathrm{D} 45]\}\end{array}$ \\
\hline $\begin{array}{l}\text { Program to Sanitize the Immediate Physical } \\
\text { Environment }\end{array}$ & $=[(\mathrm{P} 10$ to $\mathrm{P} 17)+\mathrm{P} 03]>(\mathrm{D} 32, \mathrm{D} 33)$ \\
\hline Technical Unit & $=\{[(\mathrm{F} 03+\mathrm{F} 23)>\mathrm{P} 99]+(\mathrm{P} 13+\mathrm{P} 16)\}>\mathrm{DD} 99$ \\
\hline Unit for Control and Permitting & $\begin{array}{l}=\{\{[\mathrm{F} 22>(\mathrm{F} 13+\mathrm{F} 15)]>(\mathrm{P} 01 \text { to } \mathrm{P} 06)\}> \\
(\mathrm{DD} 01, \mathrm{DD} 02, \mathrm{DD} 04, \mathrm{DD} 07, \mathrm{DD} 08, \mathrm{DD} 13)\}+(\mathrm{F} 17>\mathrm{F} 22)+[\mathrm{P} 11>(\mathrm{D} 03, \mathrm{DD} 02, \mathrm{DD} 04, \\
\text { DD07, D29, D30, D31, DD12) }]\end{array}$ \\
\hline Executive Direction for Basic Sanitation & $=[(\mathrm{F} 01$ to $\mathrm{F} 14)>(\mathrm{P} 01$ to $\mathrm{P} 06)]>(\mathrm{D} 01, \mathrm{D} 02, \mathrm{D} 05, \mathrm{D} 10)$ \\
\hline Unit for Risk's Analysis & $=\{[\mathrm{F} 99>(\mathrm{P} 16+\mathrm{P} 17)]>\mathrm{DD} 99\}+\{[(\mathrm{F} 01+\mathrm{F} 05+\mathrm{F} 06)>(\mathrm{P} 01$ to $\mathrm{P} 16)]+\mathrm{P} 13\}>\mathrm{D} 99$ \\
\hline \multicolumn{2}{|c|}{ SOME COMMON ENVIRONMENTAL HEALTH AGGREGATES AND ITS POSSIBLE EQUIVALENTS } \\
\hline Drinking water supply & $=\{\mathrm{F} 99>[(\mathrm{P} 01$ to $\mathrm{P} 05)+(\mathrm{P} 10$ to $\mathrm{P} 17)]\}>(\mathrm{D} 01, \mathrm{D} 02)$ \\
\hline Water and sanitation & $=(\mathrm{F} 99>\mathrm{P} 99)>(\mathrm{DD} 01, \mathrm{DD} 02, \mathrm{DD} 03)$ \\
\hline Environmental audit & $=[(\mathrm{F} 07+\mathrm{F} 12+\mathrm{F} 13+\mathrm{F} 14+\mathrm{F} 16+\mathrm{F} 18)>(\mathrm{P} 01$ to $\mathrm{P} 10)]>[(\mathrm{DD} 01$ to DD13 $), \mathrm{DD} 15, \mathrm{DD} 16]$ \\
\hline $\begin{array}{l}\text { Environmental Health Impact Assessment } \\
\text { (EHIA) }\end{array}$ & $=[(\mathrm{F} 07+\mathrm{F} 08+\mathrm{F} 09+\mathrm{F} 18)>(\mathrm{P} 01$ to $\mathrm{P} 07)]>\mathrm{DD} 99$ \\
\hline
\end{tabular}




\section{Aggregates}

In practice, activities can be grouped ("aggregates") in order to build the job theme to be assigned to a person or a unit within an EHS. Given an aggregate described by words, there exists a number of acceptable ways to "translate" that to the "EHSA algebra", but a symbolic expression in said algebra has generally only one description in words, therefore being more precise. Translation examples worked over some Latin American cases are given (Table 7), as well as the symbolic equivalent of some usual aggregates.

\section{Conclusions}

1) The EH practitioner will find in this paper a probably useful panorama of his or her field as understood in a number of countries, and the theorist might find interesting the constituents approach. The EH extent examination revealed the necessity of some systematization, hence the suggestion to disassemble $\mathrm{EH}$ problems/activities so as to identify its three essential constituents (determinants, processes, functions) and to use a way (EHSA algebra) to reassemble them in order to define any activity.

2) The EHS persons and institutions could have, with the use of this conceptual tool, the means to objectively establish, allocate and assess the scope of their work and their particular position vis-à-vis related entities.

3) The EHSA algebra may work, in this context, as an operative means for intercommunication, teaching and research because it can provide a common symbolic language beyond idiomatic and cultural differences.

4) The author believes that the methodology of disassembling into determinants, processes and functions, and the reassembling as shown, could be useful not only for environmental health but also for other technical/scientific fields.

\section{Conflicts of Interest}

The author declares no conflicts of interest regarding the publication of this paper.

\section{References}

[1] Mish, F.C. (1993) Merriam-Webster's Collegiate Dictionary, Tenth Edition. Encyclopedia Britannica, London.

[2] Environmental Protection Agency (2007) Browse EPA Topics/Glossary. https://search.epa.gov/epasearch/?querytext=Environment\&areaname

[3] Institute of Medicine of the National Academies (2007) Roundtable on Environmental Health Sciences, Research, and Medicine. Workshop \#13, Washington DC.

[4] Craft, E., Donnelly, K., Neamtiu, I., McCarty, K., Bruce, E., Surkova, I., Kim, D., Uhnakova, I., Gyorffy, E., Tesarova, E. and Anderson, B. (2006) Prioritizing Environmental Issues around the World: Opinions from an International Central and Eastern European Environmental Health Conference. Environmental Health Perspectives, 114, 1813-1817.

[5] MacArthur, I. and Bonnefoy, X. (1997) Environmental Health Services in Europe 
1/An Overview of Practice in the 1990s. WHO Regional Publications. European Series, 76, 1-177.

[6] Yassi, A., Kjellström, T., deKok, T., \&Guidotti, T. (1998) Basic Environmental Health. Preliminary Version, WHO/United Nations Environment Programme, UNEP/UNESCO/Council of Rectors of European Universities, CRE. Geneva, 7.

[7] PAHO/WHO Representation in Costa Rica (1994) Sanitation Technicians. San José. (In Spanish)

[8] PAHO/WHO (1998) Executive Committee, 122nd Session. Strategic and Programmatic Orientations for the Pan American Sanitary Bureau, 1999-2002, Washington DC, 32-34.

[9] Our Planet, Our Health (1992) Report of the World Health Organization Commission on Health and Environment-Contents: iii to vi. Geneva. https://apps.who.int/iris/handle/10665/37933

[10] World Health Organization/Regional Office for Europe (2009) The DPSEEA Model of Health-Environment Interlinks. http://www.euro.who.int/EHindicators/Indicators/20030527_2?

[11] Agenda 21 (1992) United Nations Conference on Environment and Development.Rio de Janeiro, 3-14 June 1992.

https://sustainabledevelopment.un.org/outcomedocuments/agenda21

[12] Department of the Environment and Local Government, Ireland, EPA (2010) The Environmental Protection Agency. https://www.gov.ie/en/help/departments/

[13] Royaume du Maroc (2006) Secrétariatd'Etatauprés du Ministère de l'Energie, des Mines, de l'Eau et de l'Environnement, chargé de l'Eau et de l'Environnement. ContexteInstitutionnel, Juridiqueet Financier. https://www.environnement.gov.ma/fr/\#

[14] Agência Portuguesa do Ambiente (2010) Ministério do Ambiente e do Ordenamento do Território. Missão e Atribuições. https://apambiente.pt/index.php?ref=16

[15] Environmental Protection Agency (2007) About EPA/Our Mission. https://www.epa.gov/aboutepa/our-mission-and-what-we-do

[16] Environmental Protection Agency (2007) Browse EPA Topics/Alphabetical List. https://www.epa.gov/environmental-topics

[17] Environmental Protection Agency (2007) Frequent Questions/Does EPA Handle All Environmental Concerns?

https://usepa.servicenowservices.com/ecss?id=kb_article_view\&sys_id=62ed8a881b $\underline{\text { f024109513859ce54bcb49 }}$

[18] Schaefer, M. (1998) Guidelines for Strengthening Environmental Health Services. WHO Interregional Meeting on the Guidelines for the Strengthening of Environmental Health Services towards Improved Governmental Action on Environmental Determinants of Health, 25-28 May 1998, Geneva. 